\title{
HUBUNGAN ANTARA RATIO NETROFIL LIMFOSIT DENGAN KLASIFIKASI RISIKO PADA LEUKEMIA LIMFOBLASTIK AKUT
}

\author{
${ }^{1}$ Yunita Batara Paarrang \\ ${ }^{2}$ Max F.J. Mantik \\ ${ }^{2}$ Stefanus Gunawan
}

\author{
${ }^{1}$ Kandidat Skripsi Fakultas Kedokteran Universitas Sam Ratulangi \\ ${ }^{2}$ Bagian Ilmu Kesehatan Anak Fakultas Kedokteran Sam Ratulangi \\ Email: yunitabatara@gmail.com
}

\begin{abstract}
Leukemia is a primary malignant disease that has dangerous risk of death. Acute lymphoblastic leukemia is a cancer mostly diagnosed in children. Prognostic assessment of acute lymphoblastic leukemia depend on the type of the risk, which is classified into high risk or standard risk. Prognostic assessment of acute lymphoblastic leukemia can be determined by some criteria and one of them is by observing the total of leukocyte in laboratory test. Reduction of neutrophil and increased of limphocyte mostly in ALL. The purpose of this study understanding the relationship between neutrophil to lymphocyte ratio and the risk classification of acute lymphoblastic leukemia. The research is an analytical retrospective using survey method. The research samples are patient with acute lymphoblastic leukemia who were admited at pediatric department of RSUP Prof. Dr. R. D. Kandou Manado during the period of January 2010-October 2014. Resources were taken from the medical records of RSUP Prof. Dr. R. D. Kandou Manado. Result: From the 46 samples, there are 39 samples that suffered from ALL at the age of 1-10 years old and most of them are boys. Twenty four samples are classified as high risk and 22 are classified as standard risk. According to the bivariate analysis, value of $p=0,432>0,05$. Conclusion: There is no relationship between neutrophil to lympocyte ratio and the risk classification for acute lymphoblastic leukemia.
\end{abstract}

Keywords: acute lymphoblastic leukemia, high risk, standard risk, neutrophil to lymphocyte ratio

\begin{abstract}
Abstrak: Leukemia merupakan penyakit keganasan primer yang memiliki risiko berbahaya menyebabkan kematian. Leukemia limfoblastik akut (LLA) adalah penyakit keganasan yang paling sering didiagnosis pada anak-anak. Penilaian prognosis leukemia limfoblastik akut tergantung pada jenis risiko yang diderita, risiko tinggi atau risiko standar. Penilaian prognosis pada leukemia limfoblastik akut ditentukan oleh beberapa kriteria salah satunya melihat jumlah leukosit dari hasil pemeriksaan laboratorium. Penurunan jumlah netrofil dan peningkatan jumlah limfosit sering terjadi pada LLA. Tujuan penelitian ini untuk mengetahui hubungan ratio netrofil limfosit dengan klasifikasi risiko pada leukemia limfoblastik akut. Penelitian ini bersifat analitik dengan metode survei retrospektif terhadap pasien dengan penyakit leukemia limfoblastik akut di Bagian Ilmu Kesehatan Anak RSUP Prof. Dr. R. D. Kandou Manado selama periode Januari 2010-Oktober 2014. Sumber data didapatkan dari rekam medik di RSUP Prof. Dr. R. D. Kandou Manado. Hasil: didapatkan dari 46 sampel terdapat 39 sampel yang menderita LLA pada usia 1-10 tahun, laki-laki lebih banyak menderita LLA, 24 sampel dengan kelompok risiko tinggi dan 22 sampel dengan kelompok risiko standar. Hasil analisis bivariat menunjukkan nilai $\mathrm{p}=0,432>0,05$. Simpulan: Tidak ada hubungan antara ratio netrofil limfosit dengan klasifikasi risiko pada leukemia limfoblastik akut.
\end{abstract}

Kata kunci: Leukemia limfoblastik akut, risiko tinggi, risiko standar, ratio netrofil limfosit. 
Leukemia merupakan keganasan primer yang ditandai dengan proliferasi sel-sel patologis dan sering terjadi pada anakanak. Leukemia limfolastik akut adalah jenis kanker yang berciri khas infiltrasi progresif dari sel limfoid imatur dari sumsum tulang dan organ limfatik yang dikenal sebagai limfoblas. Oleh sebab itu penilaian prognosis juga didasarkan oleh jumlah leukosit yang dikategorikan sebagai risiko tinggi atau risiko standar. Leukemia limfoblastik akut paling sering menyerang anak-anak di bawah umur 15 tahun dengan puncak insiden usia 2-5 tahun. ${ }^{1-3}$

Berdasarkan jenis risiko, LLA dibagi menjadi dua kategori yaitu LLA dengan risiko tinggi dan risiko standar. Penilaian prognosis dan kemungkinan penyembuhan jangka panjang pada LLA bergantung pada gambaran klinis, laboratorium dan pegobatan. Untuk membantu diagnosis dari leukemia limfoblastik akut maka perlu dilakukan pemeriksaan hematologi dan pemeriksaan sumsum tulang. Pasien dikategorikan risiko tinggi jika berumur $<1$ tahun atau $>10$ tahun, leukosit $>50.000 \mathrm{x}$ $10^{9} / \mathrm{L}$, Massa mediastinum $>2 / 3$ dari diameter rongga toraks, terdapat sel leukemia di cairan liquor serebrospinal, Tcell leukemia dan mixed leukemia. Dan pada risiko standar tidak didapatkan tandatanda dari risiko tinggi. ${ }^{1,2}$

Respon imun terhadap leukemia limfoblastik akut adalah penurunan jumlah netrofil akibat gangguan pembentukan maupun maturasi sel dan terjadi peningkatan limfosit atau penurunan ratio netrofil limfosit (RNL) ${ }^{4,5}$ Pada hepatocellular carcinoma (HCC), RNL dapat dijadikan sebagai prediktor. Dan pada beberapa jenis kanker seperti kanker pankreas, RNL dapat dijadikan sebagai penanda prognostik. ${ }^{6,7}$ Berdasarkan latar belakang masalah tersebut, peneliti ingin melakukan penelitian untuk mengevaluasi hubungan antara ratio netrofil limfosit dengan klasifikasi risiko pada pasien leukemia limfoblastik akut.

\section{METODE PENELITIAN}

Jenis penelitian yang digunakan adalah deskriptif analitik dengan metode survei retrospektif, dilakukan pengambilan data rekam medik terhadap pasien dengan penyakit leukemia limfoblastik akut di Bagian Ilmu Kesehatan Anak RSUP Prof. Dr. R. D. Kandou Manado selama periode Januari 2010-Oktober 2014. Tempat penelitian dilakukan di Pusat Kanker Anak RSUP Prof. Dr. R. D. Kandou Manado. Sampel adalah semua anak yang menderit leukemia limfoblastik akut di Bagian Ilmu Kesehatan Anak RSUP Prof. Dr. R. D. Kandou Manado, dengan kriteria inklusi pasien yang data dan hasil rekam medisnya lengkap di Pusat Kanker Anak RSUP Prof. Dr. R. D. Kandou periode Januari 2010Oktober 2014.

\section{HASIL PENELITIAN}

Berdasarkan hasil penelitian yang dilakukan di Pusat Kanker Estella RSUP Prof. Dr. R. D. Kandou, beberapa karakterisktik sampel dapat dilihat pada tabel berikut:

Tabel 1. Distribusi sampel berdasarkan umur

\begin{tabular}{lll}
\hline Usia & Frekuensi & $\mathbf{( \% )}$ \\
\hline$<1$ tahun & 0 & 0 \\
$1-10$ tahun & 39 & 89,1 \\
$>10$ tahun & 6 & 10,9 \\
\hline Total & $\mathbf{4 6}$ & $\mathbf{1 0 0}$
\end{tabular}

Tabel 1 menunjukkan bahwa responden terbesar terdapat pada usia 1-10 tahun sebanyak 89,1\% diikuti usia >10 tahun sebanyak 10,9\%. 
Tabel 2. Distribusi sampel berdasarkan jenis kelamin

\begin{tabular}{|c|c|c|}
\hline Jenis kelamin & Frekuensi & $(\%)$ \\
\hline Laki-laki & 24 & 52,2 \\
\hline Perempuan & 22 & 47,8 \\
\hline Total & 46 & 100 \\
\hline $\begin{array}{l}\text { Dari tabel di } \\
\text { dengan jenis ke }\end{array}$ & $\begin{array}{l}\text { an sampel } \\
\text { ebih banyak }\end{array}$ & $\begin{array}{l}\text { dengan persentase } 52 \text {, } \\
\text { perempuan dengan perse }\end{array}$ \\
\hline \multicolumn{3}{|c|}{ Tabel 3. Distribusi sampel berdasarkan risiko } \\
\hline Risiko LLA & Frekuensi & $(\%)$ \\
\hline Risiko Standar & 22 & 47,8 \\
\hline Risiko Tinggi & 24 & 52,2 \\
\hline
\end{tabular}

Tabel diatas menunjukkan sampel dengan risiko tinggi sebanyak 52,2\% dan disusul dengan risiko standar sebanyak 47,8

Tabel 4. Hubungan ratio netrofil limfosit dengan klasifikasi risiko pada leukemia limfoblastik akut.

\section{RNL}

\begin{tabular}{lllllll} 
& Mean & Median & $\begin{array}{l}\text { St. } \\
\text { Deviasi }\end{array}$ & $\begin{array}{l}\text { Nilai } \\
\text { Maksimum }\end{array}$ & $\begin{array}{l}\text { Nilai } \\
\text { Minimum }\end{array}$ & Nilai p \\
\hline $\begin{array}{l}\text { Risiko } \\
\text { Standar }\end{array}$ & 0,21 & 0,21 & 0,15 & 0,46 & 0,00 & \\
$\begin{array}{l}\text { Risiko } \\
\text { Tinggi }\end{array}$ & 0,22 & 0,25 & 0,14 & 0,57 & 0,00 & $0,432^{*}$ \\
\hline
\end{tabular}

Ket:* Uji Chi-Square test

Hasil uji statistik uji Chi-Square pada tingkat kepercayaan 95\%, didapatkan nilai sig. sebesar 0,432. Hal ini menunjukkan bahwa nilai $\mathrm{p}>0,05$.

\section{BAHASAN}

Hasil analisis yang dilakukan memperlihatkan bahwa rata-rata usia sampel anak dalam penelitian ini 3 tahun dengan usia terbanyak 1-10 tahun, 1 tahun usia termuda dan 14 tahun adalah usia tertua. Hasil penelitian yang dilaporkan oleh Tehuteru ES di Rumah Sakit Kanker Dharmais didapatkan bahwa kelompok usia 1 sampai < 5 tahun merupakan kelompok usia terbanyak. ${ }^{8}$ Jumlah sampel laki-laki yang menderita LLA lebih banyak dari perempuan. Hasil penelitian ini mirip yang dilaporkan oleh Widiaskara $d k k$ dalam penelitiannya di RSU Dr. Soetomo didapatkan bahwa ratio laki-laki lebih tinggi dari perempuan. ${ }^{9}$ Dan yang menderita risiko tinggi lebih banyak dibanding risiko standar.

Hasil analisis hubungan antara ratio netrofil limfosit dengan klasifikasi risiko pada leukemia limfoblastik akut menunjukkan tidak ada hubungan antara keduanya dengan nilai $\mathrm{p}>0,05$. Nilai ratio netrofil limfosit diambil pada pemeriksaan pertama atau pada pemeriksaan awal pasien yang didiagnosis LLA dan menghubungkannya dengan klasifikasi risiko. Berdasarkan protokol Indonesia 2013, risiko tinggi jika usia,1 tahun atau $>10$ tahun, jumlah leukosit $>50.000 \mathrm{x}$ $10^{9} / \mathrm{L}$, telah terjadi penyebaran sel 
luekemia ke mediastinum, cairan otak, Tcell leukemia dan pada risiko standar tidak ditemukan tanda-tanda kriteria seperti pada risiko tinggi. ${ }^{1}$ Pada umumnya anak dengan risiko standar mempunyai prognosis yang lebih baik dibanding dengan risiko tinggi. ${ }^{5}$ Pada beberapa jenis kanker seperti kanker pankreas dan hepatocelluler carcinoma, RNL dapat dijadikan sebagai prediktor bahkan penanda prognostik. Pada kanker pankreas ratio netrofil limfosit dapat menjadi penanda prognostik pada pasien yang telah menerima kemoterapi paliatif. $^{6,7}$ Namun pada penelitian ini belum ditemukan hubungan RNL dengan klasifikasi risiko pada leukemia limfoblastik akut.

\section{SIMPULAN DAN SARAN}

Tidak ada hubungan antara ratio netrofil limfosit dengan klasifikasi risiko pada leukemia limfoblastik akut. Berdasarkan hasil penelitian, peneliti menyarankan untuk melakukan penelitian lebih lanjut mengenai ratio netrofil limfosit dengan klasifikasi risiko dalam jumlah sampel yang lebih banyak dan cakupan lebih luas.

\section{DAFTAR PUSTAKA}

1. UKK Hematoonkologi. Protokol pengobatan leukemia limfoblastik akut anak. Jakarta: UKK HO;2013.

2. National cancer institute. General information about childhood acute lymphoblastic leukemia. [Online]; Update 2014 Okt 30 [cited 2014
November 2]. Available from: http://www.cancer.gov/cancertopics/p dq/treatment/childALL/Patient/page1.

3. Kanwar VS, MBBS, MBA, MRCP, FAAP. Pediatric acute limphoblastic leukemia.[Online]; Update 2014 Sep 30 [cited 2014 Oktober 9]. Available from:

http://emedicine.medscape.com/articl e/990113-overview

4. Price SA, Wilson LM. Pathophysiology: clinical concepts of disease processes. $6^{\text {th }}$ ed. Jakarta: EGC; 2005.

5. Hoffbrand AV, Moss PAH. Leukemia limfoblastik akut in Essential haematology. $6^{\text {th }}$ ed. Jakarta: EGC; 2013.

6. Xiao WK, Chen D, Li SQ, Fu FJ, Peng BG, Liang LJ. Prognostic significance of neutrophil-lymphocyte ratio in hepatocellular carcinoma: a meta-analysis. BMC Cancer. 2014;14:117.

7. Xue $P$, Kanai M, Mori $Y$, Nishimura $T$, Uza N, Kodama $\mathbf{Y}$, et. al. Neutrophil-to-lymphocyte ratio for predicting palliative chemotherapy outcomes in advanced pancreatic cancer patients. Cancer Medicine.2014;3:406-15.

8. Tehuteru ES. Gambaran tingkat remisi pada leukemia limfoblastik akut setelah fase induksi di bangsal kanker anak RS kanker darmais. Indonesia Journal of Cancer. 2011:h.159-62.

9. Widiaskara IM, Permono B, Ugrasena IDG, Ratwita M. Luaran pengobatan fase induksi pasien leukemia limfoblastik akut pada anak. Sari Pediatri. 2010;12:128-30. 